\title{
Rancang Bangun Alat Pengawasan Kondisi Penderita Vertigo Menggunakan Accelerometer Berbasis Mikrokontroler
}

\author{
Yulastri ${ }^{1}$, Era Madona ${ }^{2 *}$, Efrizon \\ ${ }^{12} 3$ Jurusan Teknik Elektro Politeknik Negeri Padang \\ emadona38@gmail.com \\ Kampus Politeknik Negeri Padang, Limau Manis Padang
}

\begin{abstract}
This research designs and makes low-cost portable devices to monitor risk patients losing their balance such as vertigo patients and cause dizziness, fall or not. This tool can determine the patient condition and send information in SMS notification and telephone calls to the patient's family. This tool uses ATmega 328 (Arduino Uno) and tilt sensor HMC5883L (accelerometer) GY-273 as the patient's body tilt detector and GSM SIM800L module for sending SMS notifications and phone calls for remote information while for short range notifications used LEDs and Buzzers. The position detection of vertigo patients works by reading the slope of the patient's body with a tilt sensor (accelerometer) and if the patient's position is no longer robust or unbalanced, then this condition trigger the GSM SIM800L module activate phone calls. When the patient falls and presses the push button, this condition ask the GSM SIM800L module sending SMS notifications. The results of testing performed on the device in detecting falls as much as 30 times, obtained the value of the sensitivity of dizziness activity by $87 \%$ and the value of sensitivity on activity fell by $90 \%$. The system requires an average of 8 seconds after the activity falls to send SMS notifications to users of telephone numbers, and also requires an average of 5 to 6 seconds after dizziness to make phone calls to users of telephone numbers. It is expected that the making of this tool can ease monitoring in vertigo patients while on the move
\end{abstract}

Keywords:vertigo, accelerometer, monitoring system, low cost

Abstrak-Penelitian ini mendesain dan membuat alat portable berbiaya rendah untuk mengawasi dan memantau pasien beresiko hilang keseimbangan seperti vertigo. Kehilangan keseimbangan dapat berupa insiden pusing atau jatuh. Alat ini dapat mengetahui keadaan pasien kemudian mengirimkan informasi berupa SMS dan panggilan telepon kepada keluarga pasien. Sistem ini menggunakan ATmega 328 (Arduino Uno) dan sensor kemiringan HMC5883L (accelerometer) GY-273 sebagai pendeteksi kemiringan tubuh pasien serta modul GSM SIM800L sebagai modul pengiriman notifikasi SMS dan panggilan telepon untuk penginformasian jarak jauh sedangkan untuk notifikasi jarak dekat digunakan LED dan Buzzer. Alat pendeteksi posisi pasien vertigo ini bekerja dengan membaca kemiringan dari tubuh pasien dengan sensor kemiringan (accelerometer) dan apabila posisi pasien terbaca tidak lagi tegap atau tidak seimbang, maka kondisi tersebut akan membuat modul GSM SIM800L mengaktifkan panggilan telepon. Saat pasien terjatuh dan menekan tombol push button, maka kondisi tersebut akan membuat modul GSM SIM800L mengaktifkan pengiriman notifikasi SMS. Hasil pengujian yang dilakukan pada alat dalam mendeteksi jatuh sebanyak 30 kali, diperoleh nilai sensitifitas pada aktifitas pusing sebesar $87 \%$ dan nilai sensitifitas pada aktifitas jatuh sebesar $90 \%$. Sistem membutuhkan rata-rata 8 detik pasca aktifitas jatuh untuk mengirimkan notifikasi sms kepada pengguna nomor telepon, dan juga membutuhkan rata-rata 5 sampai 6 detik pasca aktifitas pusing untuk melakukan panggilan telepon kepada pengguna nomor telepon. Diharapkan pembuatan alat ini dapat meringankan pemantauan pada pasien vertigo saat beraktivitas.

Kata kunci:vertigo, accelerometer, sistem monitoring, biaya rendah

(C) 2018Elektron Jurnal Ilmiah

\section{PENDAHULUAN}

Kesehatan adalah hal sangat penting dalam kehidupan. Dengan menjalankan pola hidup sehat dan pola makan teratur dapat mengurangi resiko menderita penyakit. Namun terkadang kesadaran akan pola hidup sehat dan pola makan teratur masih terabaikan. Banyak penyakit dan gejala-gejala yang timbul akibat pola hidup dan pola makan yang tidak teratur salah satunya vertigo. Vertigo merupakan sakit kepala yang berbeda dari gejala sakit kepala biasa dan migraine. Vertigo adalah suatu sensasi gerakan atau rasa gerak dari tubuh atau lingkungan sekitarnya dengan gejala yang timbul, terutama dari jaringan otonomik yang disebabkan oleh gangguan alat keseimbangan tubuh yang ditandai dengan perasaan berputar, dunia serasa bergoyang, benda sekeliling berputar, rasa mau jatuh bahkan adakalanya benar-benar terjatuh, disertai dengan mual, muntah, keringat dingin serta merasa lebih baik jika berbaring. Terkadang seorang penderita vertigo itu sendiri pada awalnya tidak mengetahui jenis gejala maupun penyakit yang dideritanya karena gejala yang timbul datang secara tiba-tiba. Karena 
gejala yang timbul secara tiba-tiba ini bisa mengakibatkan penderita vertigo terjatuh maka diperlukan tindakan pengawasan untuk penderita vertigo ini.

Pengawasan ini sangat penting dilakukan agar tidak terjadi hal-hal yang tidak diinginkan. Keluarga terdekat harus selalu menemani dan mengawasi apa saja yang mereka kerjakan. Sehingga apabila terjadi sesuatu dapat langsung ditangani agar tidak berakibatkan fatal. Akan tetapi hal tersebut bukanlah hal yang mudah dilakukan karena para keluarga tidak dapat memantau apa yang terjadi dengan penderita vertigo.

Untuk mengawasi dan memantau penderita vertigo apakah terjadi insiden pusing, jatuh atau tidak, diperlukan suatu alat yang berfungsi untuk mengetahui keadaan posisi penderita vertigo itu sendiri menggunakan accelerometer dari jarak dekat maupun jauh. Beberapa penelitian terkait monitoring kesehatan telah dilakukan, Anagha Jamthe dkk, menggunakan force sensor yang diletakkan pada kaus kaki pasien parkinson, menggunakan RSSI indicator untuk dikirimkan ke base station (BS), dengan nilai RSSI akan diketahui posisi pasien[1]. ] Harun, M Udin Rasyid dkk mengembangkan mobile monitoring Electromyogram (EMG) berbasis wsn menggunakan e-health sensors platform, hasil pembacaan sensor akan ditampilkan pada aplikasi mobile. Pasien dapat melihat berapa persen ketegangan otot secara realtime. Selain itu pasien dapat melihat data EMG mereka sebelumnya[2]. Menggunakan sensor DHT22 kemudian ditampilkan pada LCD untuk monitoring pasien ambient[3]. Penelitian untuk monitoring detak jantung untuk pasien beresiko berbasis IoT juga telah dilakukan oleh Andrej skraba dkk, menggunakan ESP8266 sebagai mikroprosesor dan pulse sensor data detak jantung kemudian ditampilkan pada smartphone[4].

Semua penelitian diatas hanya fokus pada monitoring dan menggunakan komunikasi jaringan internet $[1,2,4]$ yang tentu saja menambah biaya, selain itu tidak ada peringatan dan pemberitahuan baik kepada dokter atau keluarga pasien beresiko jika terjadi sesuatu pada pasien. Pada penelitian kami membuat alat portable berbiaya rendah untuk mengawasi dan memantau pasien beresiko vertigo apakah terjadi insiden pusing, jatuh atau tidak. Alat ini dapat mengetahui keadaan pasien vertigo kemudian mengirimkan informasi berupa SMS dan panggilan telepon kepada keluarga pasien. diharapkan pembuatan alat ini dapat meringankan pemantauan pada pasien vertigo saat beraktivitas.

\section{METODE PENELITIAN}

Pada bagian ini akan dijelaskan tentang cara kerja sistem yang terdapat dalam garis besar perancangan sistem dan diikuti dengan penjelasan tentang perangkat keras (hardware) yang terdiri dari beberapa bagian yang berfungsi untuk mengelola data.
Kemudian diikuti dengan perancangan dan pembuatan perangkat lunak (software) untuk mengaktifkan sistem alarm dari alat untuk pendeteksi posisi pasien meliputi buzzer dan notifikasi SMS maupun panggilan telepon.

\section{A. Blok Diagram}

Alat ini menggunakan sensor kemiringan untuk mengetahui kemiringan dari sensor yang diletakkan di dalam kotak yang bisa dikaitkan di ikat pinggang atau dimasukkan ke dalam tas agar dapat diketahui kondisi dari penderita vertigo. Sensor kemiringan accelerometer ditentukan menjadi 3 kondisi yaitu, baik-baik saja, pusing dan jatuh. Pada saat kondisi baik-baik saja LED dan buzzer tidak aktif sebagai tanda penderita dalam keadaan baik, seperti terlihat pada gambar 1 .

Selanjutnya pada kondisi kedua yaitu pusing, saat penderita mengalami pusing dan secara tidak sengaja menggerakkan badan karena keseimbangan badan yang terganggu sehingga sensor accerlerometer akan membaca pergerakan dari badan penderita yang sedang mengalami pusing. Pada saat kondisi pusing LED akan aktif berkedip secara cepat tanda penderita dalam keadaan pusing. Dan untuk kondisi pusing ini juga disediakan tombol panik yang bisa digunakan penderita vertigo jika membutuhkan pertolongan saat sedang pusing. Push button ini tidak digunakan pada kondisi pusing saat terdeteksi sensor accelero saja tetapi juga saat kondisi baik-baik saja namun penderita vertigo merasa pusing dan ingin menggunakan push button untuk menginformasikan kondisinya ke nomor tujuan. Jika penderita vertigo menekan push button tersebut maka buzzer akan berbunyi, LED akan berkedip dan sim800 akan mengirim notifikasi sms ke nomor 08239xxx. Pada kondisi terakhir yaitu jatuh, sensor kemiringan akan mengkondisikan dari penderita yang jatuh terbaring atau terlentang. Mikrokontroler akan memproses kondisi yang sudah ditentukan bahwa penderita telah terjatuh. Buzzerakan berbunyi dan LED berkedip dengan cepat sebagai notifikasi bahwa penderita terjatuh.

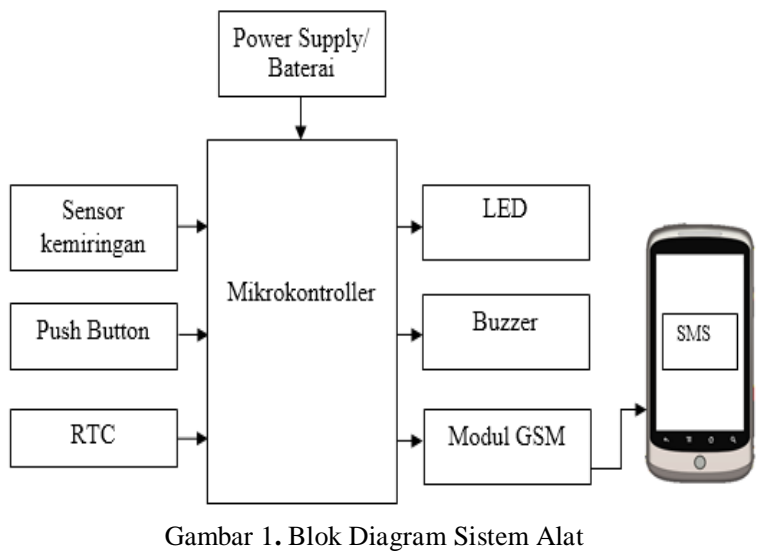

Modul GSM SIM800L yang menggunakan nomor telepon "08229xxx" akan mengirimkan SMS ke 
nomor telepon "0823911xxx" sebagai notifikasi bahwa penderita telah terjatuh dan mengirimkan sms sebagai pemberian informasi bahwa penderita sedang mengalami pusing atau terjatuh. Alat ini juga menggunakan RTC sebagai pengingat bagi penderita untuk minum obat. Pada alat ini disetting penderita vertigo minum obat 3 kali sehari yaitu pagi pukul 08.00, siang pukul 14.00, dan malam pukul 20.00. Setelah disetting maka setiap RTC menunjukkan waktu tersebut maka buzzer akan berbunyi sebagai alarm atau tanda untuk mengingatkan penderita untuk minum obat.

\section{B. Perancangan Rangkaian Elektronika}

Rangkaian ini terdiri dari pendeteksi sudut kemiringan menggunakan accelerometer GY-521 MPU6050 dan juga push button sebagai pendeteksi jatuh. LED dan buzzer berfungsi sebagai indikator dan alarm pada alat. Baterai terhubung ke pin $5 \mathrm{~V}$ dan GND arduino. Modul GSM SIM800L berfungsi untuk mengirimkan notifikasi berupa SMS dan panggilan.

Sensor accelerometer GY-521 MPU6050yang menggunakan koneksi I2C (SDA dan SCL) dimana SDA terhubung ke pin A4 dan SCL ke pin A5 mikrokontroler ATMega328.Baterai sebagai sumber tegangan mobile untuk sistem ini terhubung ke $+5 \mathrm{~V}$ dan GND mikrokontroler dan $+4 \mathrm{~V}$ ke modul GSM SIM800L.

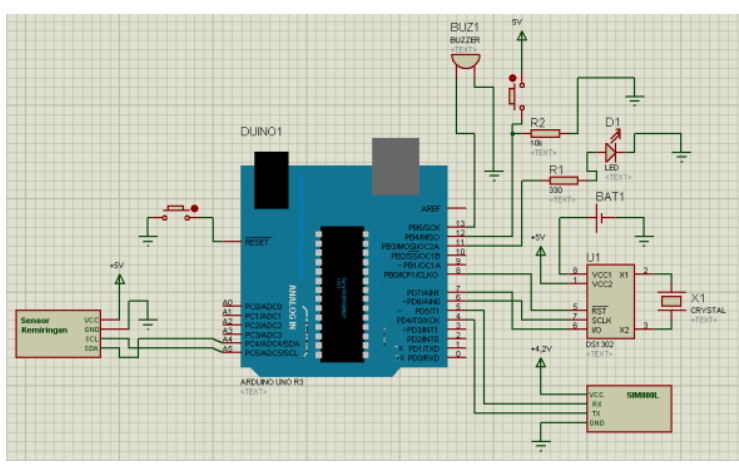

Gambar 2. Rangkaian elektronika Alat keseluruhan

Untuk mendapatkan tegangan sebesar +4VDC diperlukan sebuah DC-DC converter. Push Button berfungsi sebagai pendeteksi jatuh dari pasien vertigo yang dihubungkan ke pin 6 mikrokontroler. Untuk output LED merah dan putih dihubungkan ke pin 10 , 11 dan pin 12, sedangkan buzzer dihubungkan ke pin 13. Pada modul GSM SIM800L digunakan untuk notifikasi SMS dan panggilan telepon menggunakan koneksi Rx dan Tx yang dihubungkan ke pin 7 (Tx) dan pin 8 (Rx) mikrokontroler Arduino Uno (ATMega328)

\section{Perancangan Perangkat Lunak}

Peragkat lunak atau program yang dibuat berdasarkan flowchart yang tampak pada gambar 3 .

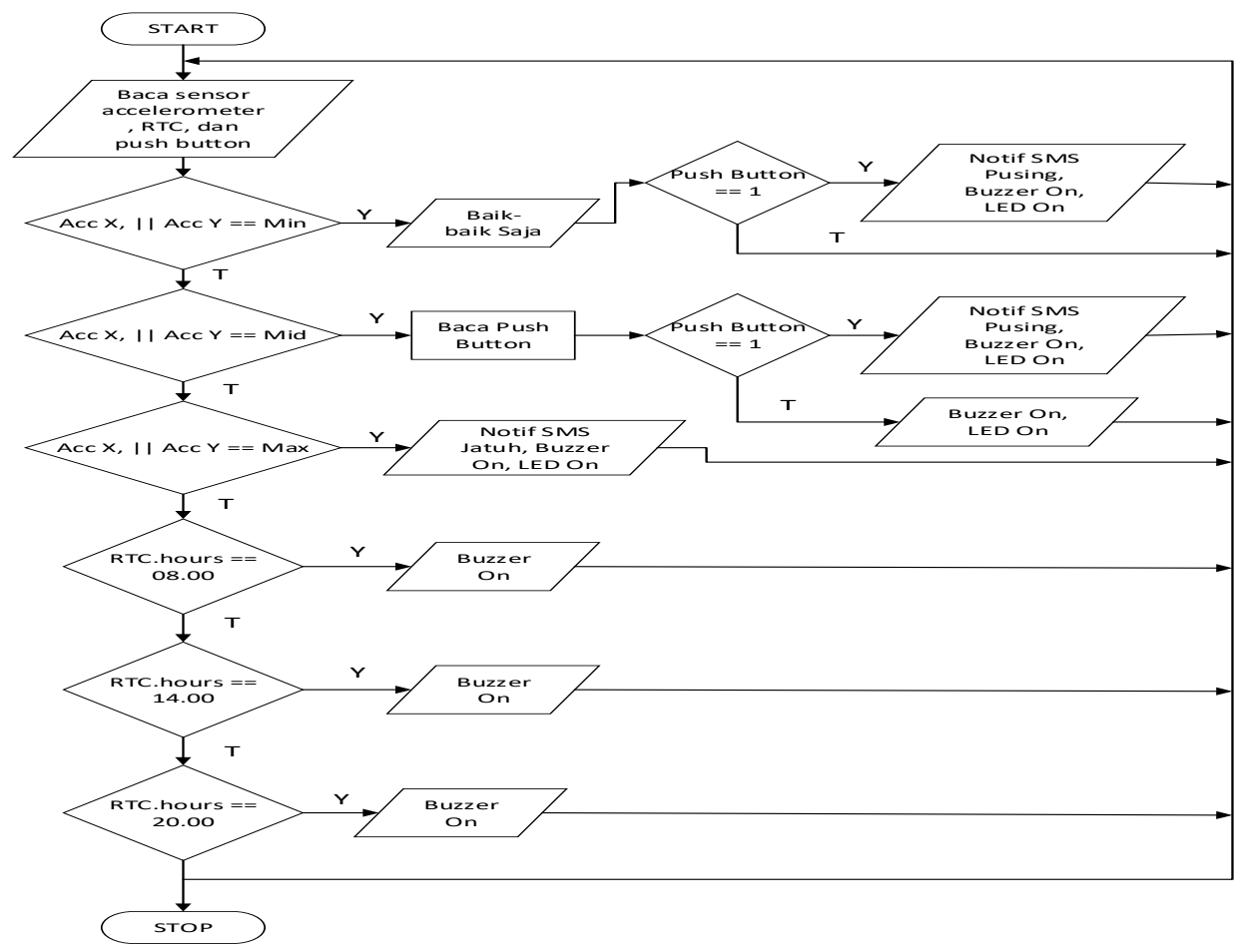

Gambar 3. Flowchart Alat 


\section{HASIL DAN PEMBAHASAN}

Pada bagian ini akan dilakukan pengujian dan analisa pada 3. Pengujian dan Analisa pada Sensor GY-521 MPU 6050, Pengujian dan Analisa pada Real Time Clock (RTC) dan Pengujian dan Analisa pada SIM800L.

\section{A. Pengujian dan Analisa pada Sensor GY-52I MPU 6050}

Untuk menguji sensor kemiringan pada accelerometer, data keluaran pada sumbu $\mathrm{X}$ dan sumbu $\mathrm{Y}$ untuk mendeteksi keadaan penderita vertigo. Kemudian data sensor ditampilkan pada serial monitor, sehingga di dapat hasilnya sebagai berikut. kondisi normal atau baik-baik saja nilai sumbu $\mathrm{x}$ dan $\mathrm{y}$ berada pada nilai minimum. Range nilai sensor kemiringaan ini adalah $16384 \mathrm{LSB} / \mathrm{g}$. untuk memperkecil range, di program dibagi 100 maka menjadi 163,84. Ketika penderita vertigo pusing, nilai sumbu $\mathrm{x}$ dan y berada pada nilai tengah dari sumbu tersebut, sedangkan untuk kondisi jatuh nilai sumbu $x$ dan y berada pada nilai maksimum.

Untuk range nilai sensor accelero saat kondisi baik-baik saja adalah 0 sampai $( \pm 45) \mathrm{LSB} / \mathrm{g}$ untuk sumbu $x$ dan y. Untuk kondisi pusing $( \pm 46) \mathrm{LSB} / \mathrm{g}$ sampai $( \pm 85) \mathrm{LSB} / \mathrm{g}$ untuk sumbu $\mathrm{x}$ dan $\mathrm{y}$. Dan untuk kondisi jatuh yaitu $( \pm 86) \mathrm{LSB} / \mathrm{g}$ sampai $( \pm 163) \mathrm{LSB} / \mathrm{g}$ untuk sumbu $x$ maupun sumbu y. Untuk kondisi jatuh ke depan dan ke belakang nilai sumbu sensor kemiringan yang berubah adalah sumbu y. Karena saat jatuh ke depan atau ke belakang yang menjadi poros putar adalah sumbu $\mathrm{x}$, jika penderita vertigo jatuh ke kiri atau kekanan nilai sumbu yang berubah adalah sumbu x karena yang menjadi poros adalah sumbu y. Sedangkan untuk nilai sumbu plus (+) atau minus (-) itu berdasarkan arah rotasi. Ketika sumbu berputar searah jarum jam maka nilai sensor akan plus (+). Ketika sumbu berputar berlawanan jarum jam maka nilai sensor menjadi minus (-).

\section{B. Pengujian dan Analisa pada Real Time Clock}

(RTC)Penggunaan RTC adalah untuk pengingat minum obat bagi penderita vertigo jika mengkonsumsi obat secara rutin. Pada alat ini penderita vertigo akan diingatkan untuk minum obat 3 kali yaitu pagi pukul 08.00WIB, siang pukul 14.00WIB, dan malam pukul 20.00WIB seperti tampak pada gambar 4, 5, 6 hasil pengujian RTC.

RTC dan mikrokontroller arduino berkomunikasi secara serial menggunakan pin SCLK pada RTC, pin data atau I/O yang digunakan untuk jalur data, dan pin RST untuk reset. RTC memiliki dua sumber supply, jadi walaupun RTC tidak terhubung ke arduino RTC tetap bisa up date waktu karena tetap terhubung ke baterai yang memang sudah terpasang di modul RTC. Jika baterai pada RTC habis atau terlepas maka RTC tidak bisa up date waktu dan harus diulangi me reset waktu dan tanggal.

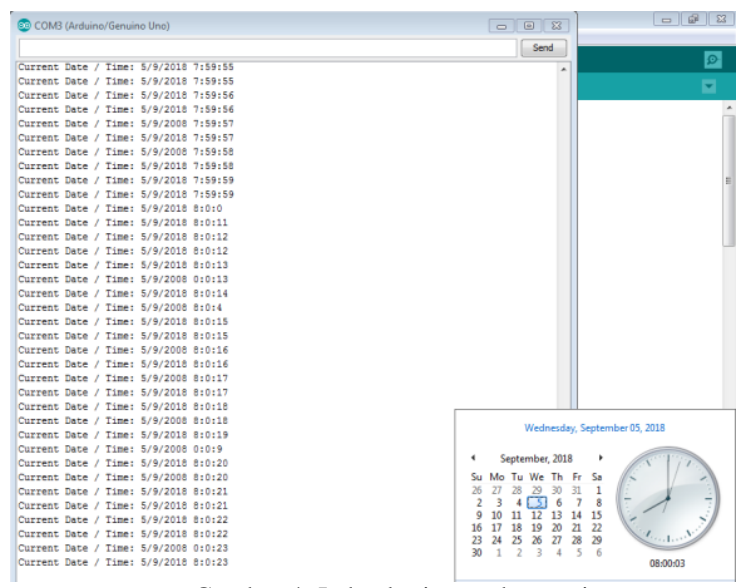

Gambar 4. Jadwal minum obat pagi

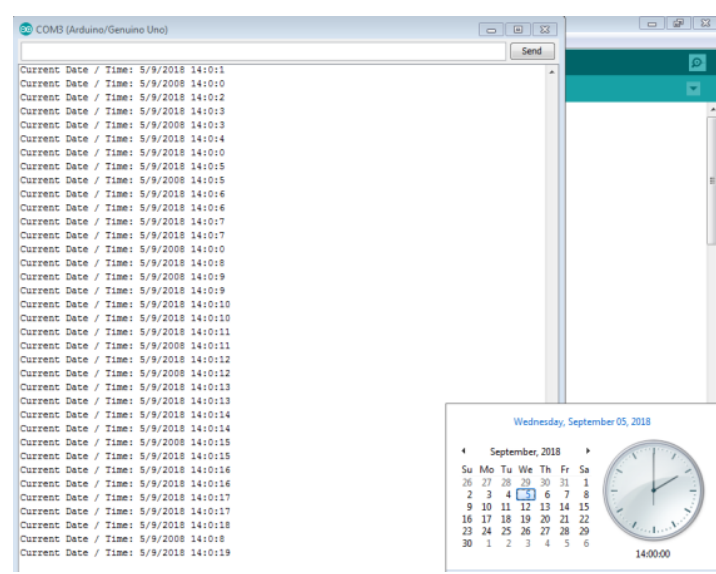

Gambar 5. Jadwal minum obat siang

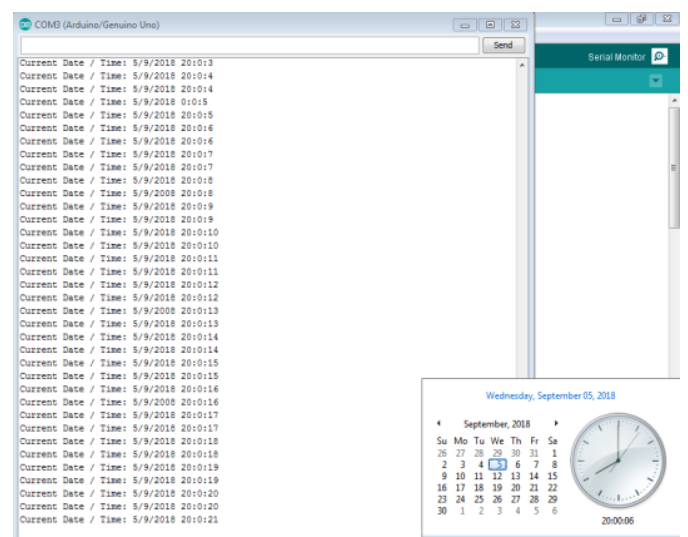

Gambar 6. Jadwal minum obat malam

\section{Pengujian dan Analisa Pada SIM $800 \mathrm{~L}$}

Pengujian terhadap GSM SIM800L dilakukan untuk mengetahui bahwa GSM ini dapat bekerja dengan baik agar bisa berkomunikasi dengan mikrokontroler sebagai penghubung ke jaringan GSM dari mikrokontroler yang dipakai sebagai pengatur kapan dan ke nomor mana SMS akan dikirim serta isi pesan teks singkat (SMS) yang akan dikirim. Keadaan yang dikirim, yaitu keadaan terjatuh dan pusing. Lama pesan masuk ke handpone berkisar 2 detik. Waktunya tergantung dengan yang kita inginkan dengan cara 
mengatur delay. contoh bentuk pembacaan dan pengirim pesan peringatan seperti gambar di bawah:

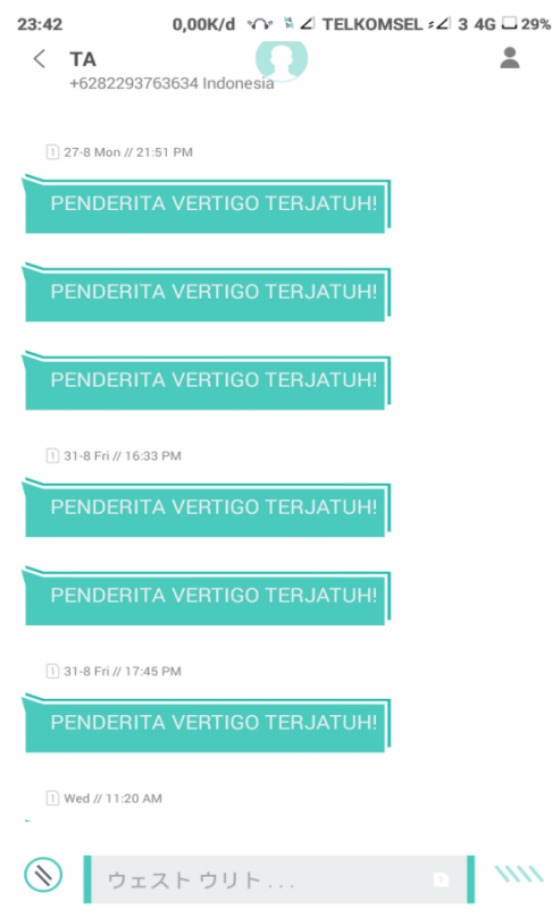

Gambar 6. Tampilan sms yang tekirim ke nomor tujuan

Modul GSM SIM800L bisa mengirimkan pesan ke nomor tujuan karena pada program arduino menggunakan perintah "AT+CMGF" yang merupakan perintah untuk mengirimkan SMS bagi modul SIM800L ini.

\section{KESIMPULAN}

Setelah dilakukan pengambilan data dan percobaan alat secara langsung dapat diambil kesimpulan sebagai berikut:

1. Untuk range nilai sensor accelero saat kondisi baik-baik saja adalah 0 sampai $( \pm 45) \mathrm{LSB} / \mathrm{g}$ untuk sumbu $x$ dan $y$. Untuk kondisi pusing $( \pm 46) \mathrm{LSB} / \mathrm{g}$ sampai $( \pm 85) \mathrm{LSB} / \mathrm{g}$ untuk sumbu $\mathrm{x}$ dan $\mathrm{y}$. Dan untuk kondisi jatuh yaitu $( \pm 86) \mathrm{LSB} / \mathrm{g}$ sampai $( \pm$ 163)LSB/g untuk sumbu x maupun sumbu $y$.

2. Modul GSM SIM800L mengirim SMS ketika penderita vertigo terjatuh, ketika menekan push button dengan kondisi pusing, dan saat baik-baik saja tetapi merasa pusing kemudian menekan push button.

3. Penderita vertigo diingatkan minum obat tiga kali sehari yaitu pada pukul 08.00WIB, pukul 14.00WIB, dan pukul 20.00WIB menggunakan RTC.

\section{REFERENSI}

[1] Anagha Jamthe, Suryadip Chakraborty, Saibal K Ghosh, and Dharma P. Agrawal School." An implementation of Wireless Sensor Networks in monitoring of Parkinson's Patients using
Received Signal Strength Indicator". IEEE International Conference on Distributed Computing in Sensor Systems,2013.

[2] Harun, M Udin Rasyid Al, Prasetyo, Doni Nadhori, Isbat Uzzin Alasiry, Ali Husein." Mobile Monitoring of Muscular Strain Sensor Based on Wireless Body Area Network". IEEE International Conference on Electronics Symposium (IES), 2015

[3] Ravi Kishore Kodali and Kopulwar Shishir Mahesh." Low Cost Ambient Monitoring using ESP8266". 2016 2nd IEEE International Conference on Contemporary Computing and Informatics (IC3I).

[4]. Andrej Škraba, Andrej Koložvari, Davorin Kofjač." Prototype of Group Heart Rate Monitoring with NODEMCU ESP8266". 017 6th MEDITERRANEAN CONFERENCE ON EMBEDDED COMPUTING (MECO), 11-15 JUNE 2017, BAR, MONTENEGRO 